\title{
Understanding the Inhibition of Mild Steel Corrosion by Dianiline Schiff Bases: a DFT Investigation
}

\author{
Salah Eddine Hachani*, Zelikha Necira, Djamel Eddine Mazouzi \\ and Nadia Nebbache \\ Laboratory of Applied Chemistry LCA, Faculty of Science, University of Biskra, B.P. 145, RP. 07000 Biskra, Algeria \\ *Corresponding author: E-mail: salaho_hachani@yahoo.fr \\ Phone number: +213791162887
}

Received: 28-08-2017

\begin{abstract}
Quantum chemical calculations at DFT/B3LYP level of theory with 6-31G, 6-311G, and 6-311G(d,p) basis sets were done to correlate the inhibition of mild steel corrosion in $1 \mathrm{M} \mathrm{H}_{2} \mathrm{SO}_{4}$ by four dianiline Schiff bases namely N,N'-Bis(benzylidene)-4,4'-dianiline (DAA), N,N'-Bis (benzylidene)-4,4'-methylenedianiline (MDAA), N,N' Bis(benzylidene)-4,4'-sulphonyldianiline (SDAA) and $\mathrm{N}, \mathrm{N}^{\prime}$-Bis(benzylidene)-4,4'-oxydianiline (ODAA) with their electronic and structural properties. Quantum chemical parameters such as the $\mathrm{E}_{\text {номо }}, \mathrm{E}_{\mathrm{LUMO}}$, energy gap $(\Delta \mathrm{E})$, dipole moment $(\mu)$, global softness $(\sigma)$, and global hardness $(\eta)$ were calculated and discussed to provide valuable explanations for the reactivity and selectivity of the studied inhibitors. The results obtained showed a certain relationship to the experimental inhibition efficiency results earlier reported.
\end{abstract}

Keywords: Dianiline Schiff bases, corrosion, inhibition, mild steel, $1 \mathrm{M} \mathrm{H}_{2} \mathrm{SO}_{4}$, DFT

\section{Introduction}

The prevention of mild steel against corrosion has attracted great attention from both academia and industry due to the important role of mild steel in several industrial applications such as storage and transportation of various chemical solutions. ${ }^{1}$ Mild steel equipments must be regularly cleaned to prevent damage and maintain the application efficiency. Acid solution is extensively used in chemical cleaning of mild steel which leads, after a certain time, to corrode its surfaces. ${ }^{2,3}$

The protection of mild steel using corrosion inhibitors is one of the most practical processes. ${ }^{4}$ Organic compounds containing heteroatoms with lone pairs of electrons (oxygen, sulfur, nitrogen, and phosphorus), aromatic rings, and $\pi$-electrons in triple or conjugated double bonds are considered to be excellent corrosion inhibitors. ${ }^{5}$ The corrosion inhibitory of such organic compounds is closely related to their adherence on metal surfaces via a physical adsorption (physisorption) which arises from electrostatic interactions between the inhibitor and the metallic surface or via chemical adsorption (chemisorption) by coordination bonds. ${ }^{6,7}$

Schiff bases are organic compounds obtained from the condensation of carbonyls and amines. This type of compounds has a well-known popularity in the field of materials science due to their potential advantages such as easy synthetic route, high purity, low toxicity, and their eco-friendly nature. ${ }^{8-10}$ The experimental studies on corrosion inhibitors have demonstrated that Schiff base molecules can be used as effective corrosion inhibitors in different aggressive media. ${ }^{11}$

Experimental techniques such as weight loss measurements, potentiodynamic polarization and electrochemical impedance spectroscopy are useful in understanding the corrosion inhibition mechanisms but they are expensive and time-consuming. ${ }^{12,13}$ Computer hardware and software advances have motivated scientists to use theoretical chemistry in the field of corrosion research. Density functional theory (DFT) method is a very reliable tool effectively used to understand the chemical reactivity and site selectivity of the molecular systems and to describe the structural nature of the inhibitor on the corrosion process. ${ }^{14}$

Theoretical investigations using density functional theory (DFT) calculations in both gas and aqueous phases have been carried out in the field of corrosion research to explore the correlations of the experimental inhibition efficiencies with the molecular structures of corrosion inhibitors. ${ }^{15-17}$ The calculated results indicated that the inhi- 
bition efficiency of each molecule depends on its molecular structure and global reactivity descriptors such as its highest occupied molecular orbital energy $\left(\mathrm{E}_{\mathrm{HOMO}}\right)$, lowest unoccupied molecular orbital energy $\left(\mathrm{E}_{\mathrm{LUMO}}\right)$, energy difference HOMO-LUMO $(\Delta \mathrm{E})$, electronegativity $(\chi)$, global hardness $(\eta)$, softness $(\sigma)$, and the fraction of electrons transferred $(\Delta \mathrm{N})$.

In a study, ${ }^{18}$ the inhibition of mild steel corrosion in sulfuric acid media by dianiline Schiff bases namely N,N'-Bis(benzylidene)-4,4'-dianiline

(DAA) $\mathrm{N}, \mathrm{N}^{\prime}$-Bis(benzylidene)-4,4'-methylenedianiline (MDAA), N,N'-Bis(benzylidene)-4,4'-sulphonyldianiline (SDAA) and N,N'-Bis(benzylidene)-4,4'- oxydianiline (ODAA) (Fig. 1) was investigated. A good inhibition activity has been reported for the four compounds under probe.

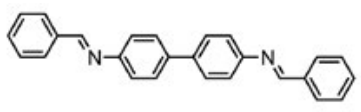

DAA
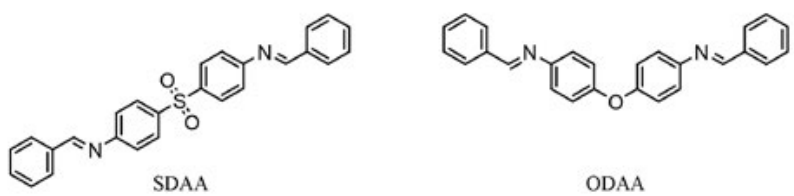

ODAA
Figure 1: Chemical molecular structures of the studied dianiline Schiff bases.

To the best of our knowledge, there is no theoretical background has been proposed to explain the relationship between the experimental protection efficiencies of the dianiline Schiff bases inhibitors and their molecular and electronic properties.

The present theoretical investigation aims to provide supportive explanations for the observed experimental results of the inhibition effects. Global chemical reactivity parameters including the energies of frontier orbitals $\left(\mathrm{E}_{\mathrm{HO}}\right.$ ${ }_{M O}$ and $\left.\mathrm{E}_{\mathrm{LUMO}}\right)$, energy gap $(\Delta \mathrm{E})$, dipole moment $(\mu)$, hardness $(\eta)$, softness $(\sigma)$, the fraction of electrons transferred $(\Delta N)$, and total energy (TE) were reported and discussed.

\section{Computational details}

Density functional theory (DFT) method is theoretical approach widely applied to predict the chemical reactivity of molecules due to its ability to give accurate geometries and electronic properties of chemical compounds. ${ }^{19}$ DFT with Beck's three parameter exchange functional along with the Lee-Yang-Parr non local correlation functional (B3LYP) has been largely used to study of chemical reactivity and selectivity of the inhibitor molecules. ${ }^{20}$ In the current contribution, calculations at DFT/B3LYP have been done in vacuo at the neutral forms of the dianiline Schiff bases molecules. 6-31G, 6-311G and 6-311G(d,p) basis sets were selected to optimize the molecular structures at minimum energy level and considered adequate enough to calculate the global reactivity descriptors for the tested molecules. The input files of the studied dianiline Schiff bases were built using Gauss View 5.0.8. ${ }^{21}$ The calculations were carried out using Gaussian 03W program package. $^{22}$

According to the Koopmans' theorem, ${ }^{23}$ electronic molecular descriptors such as the ionization potential (I) and electron affinity (A) are related to HOMO and LUMO energies and they are given by the relations 1 and 2:

$$
\begin{aligned}
& I=-E_{\text {номо }} \\
& A=-E_{\text {LUмо }}
\end{aligned}
$$

According to Pearson, ${ }^{24}$ the electronegativity $(\chi)$, global hardness $(\eta)$, and global softness $(\sigma)$ can be calculated from the ionization potential (I) and electron affinity (A) using the following equations:

$$
\begin{aligned}
& \chi=(I+A) / 2 \\
& \eta=(I-A) / 2 \\
& \sigma=1 / \eta
\end{aligned}
$$

The fraction of electrons transferred $(\Delta N)$ from the chemical species to the metal surface is calculated using Pearson's equation $^{25}$ :

$$
\Delta N=\left(\Phi-\chi_{\text {Inh }}\right) / 2\left(\eta_{F e}+\eta_{I n h}\right)
$$

Where $\Phi$ is the work function of the iron surface with the value of $4.82 \mathrm{eV}$ for Fe (110). $\chi_{\text {Inh }}$ is the absolute electronegativity of the inhibitor molecule, $\eta_{\mathrm{Fe}}$ and $\eta_{\text {Inh }}$ are the absolute hardness of iron and the inhibitor molecule respectively. In this study, we consider $\eta_{\mathrm{Fe}} 0 \mathrm{eV}$ to compute the fraction of electrons transferred $(\Delta N)$ for each inhibitor. ${ }^{26,27}$

\section{Results and Discussions 3. 1. Results of the Calculations for
Non-protonated Species}

The inhibition effects of four dianiline Schiff bases on the mild steel corrosion in $1.0 \mathrm{M} \mathrm{H}_{2} \mathrm{SO}_{4}$ solution were experimentally investigated using different techniques such as weight loss test, polarization measurements, and electrochemical impedance spectroscopy. ${ }^{18}$ The experimental results showed that the investigated compounds can act as good inhibitors and DDA exhibits the best inhi- 
bition efficacy. The experimental inhibition efficiencies of the studied compounds follow the order: $\mathrm{MDAA} \approx \mathrm{DAA}>$ SDAA > ODAA. ${ }^{18}$

In the present contribution, quantum chemical calculations have been performed to find the relationship between the molecular electronic features of the studied inhibitors and their experimental inhibition efficiencies. The optimized molecular structures of the dianiline Schiff bases inhibitors under investigation are shown in Figure 2.

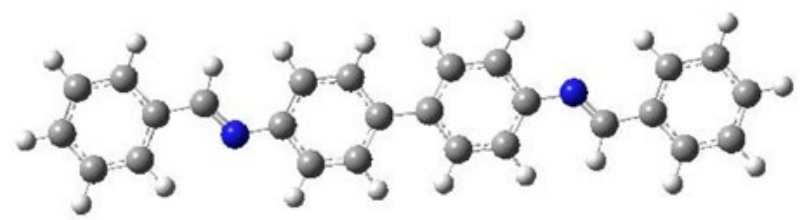

DAA
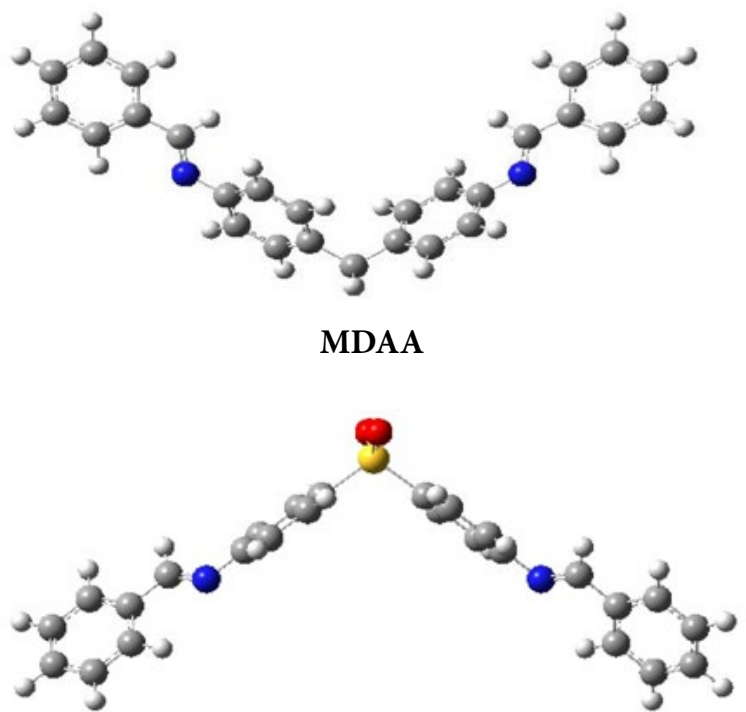

SDAA

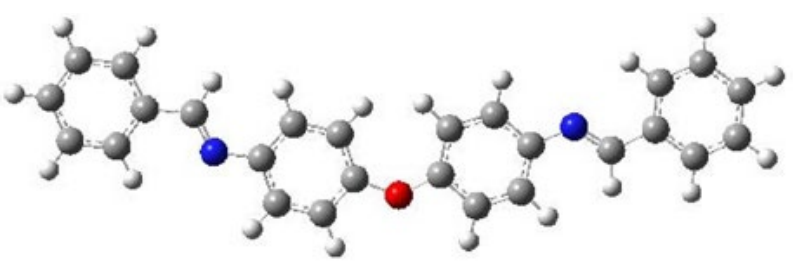

ODAA

Figure 2: Optimized molecular structures of non-protonated inhibitor molecules using B3LYP/6-31 G calculation level.

The molecular geometry is a critical parameter used to evaluate the adsorption of the inhibitor on metal surface. Molecules having planar molecular structure have a greater tendency to adsorb on metal surface than molecules having less planar geometry. ${ }^{28}$ The geometries of the molecules under probe given in Figure 3, show that DAA and ODAA are highly planar while MDAA and SDAA are less planar. The adsorbability of the tested molecules on the mild steel surface would probably be ranked as follows: $\mathrm{DAA} \approx \mathrm{ODAA}>\mathrm{SDAA} \approx \mathrm{MDAA}$, this result indicates that DAA has a greater tendency to adsorb on metal surface compared to the other studied molecules.

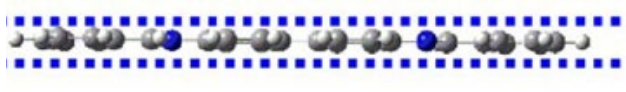

DAA

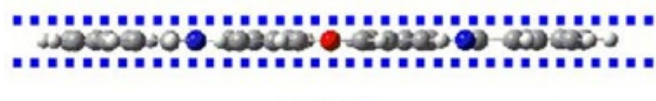

ODAA

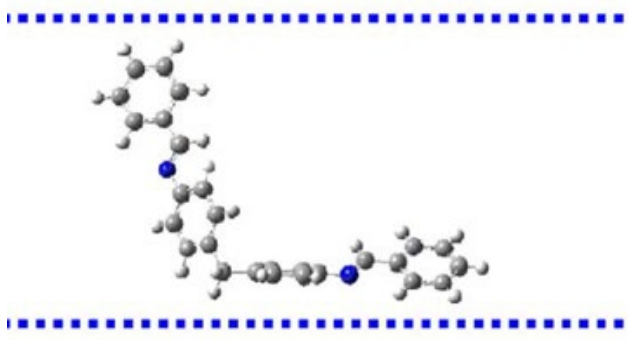

MDAA

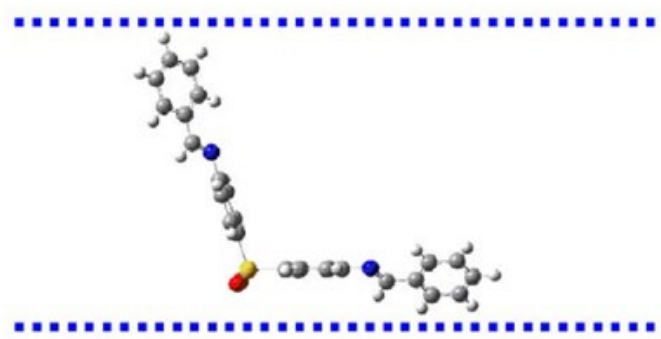

SDAA

Figure 3: Geometry planarity of the studied dianiline Schiff bases.

Beside the molecular geometries of the studied inhibitors, an analysis of other quantum chemical parameters as $\mathrm{E}_{\text {HOMO }} \mathrm{E}_{\text {LUMO }}, \Delta \mathrm{E}$, global softness $(\sigma)$, global hardness $(\eta)$, and fraction of electrons transferred $(\Delta N)$ are efficient for finding which inhibitor molecule has greater ability to donate electrons, receive electrons from the metal or bind more strongly to the metallic surface to act as suitable corrosion inhibitor.

Table 1 and 2 give the calculated quantum chemical descriptors for the molecules under probe. In the light of total energy data given in Table 1, it can be seen that the best corrosion inhibitor (DAA) has the highest total energy $(-30260.1092 \mathrm{eV})$ among the studied molecules, which confirms that DDA has highest chemical reactivity towards mild steel surface.

It is well known that inhibitor reactivity is closely related to its adsorption on metal surface via donor-acceptor 
Table 1: Calculated quantum chemical descriptors for non-protonated molecules in gas phase.

\begin{tabular}{lccccc}
\hline & TE $(\mathbf{e V})$ & $\boldsymbol{\mu}(\mathbf{D})$ & $\mathbf{E}_{\text {номо }}(\mathbf{e V})$ & $\mathbf{E}_{\text {Luмо }}(\mathbf{e V})$ & $\Delta \mathbf{E}(\mathbf{e V})$ \\
\hline 6-31G & & & & & \\
DAA & -30260.1092 & 0.0000 & -5.4975 & -2.0762 & -3.4213 \\
MDAA & -31329.6100 & 2.2011 & -5.7291 & -1.6443 & -4.0848 \\
SDAA & -45182.0792 & 7.1350 & -6.3688 & -2.1325 & -4.2363 \\
ODAA & -32305.6070 & 1.0153 & -5.4815 & -1.8293 & -3.6522 \\
\hline 6-311G & & & & & \\
DAA & -30266.3755 & 0.0000 & -5.7336 & -2.3107 & -3.4229 \\
MDAA & -31336.1285 & 2.2899 & -5.9646 & -1.8730 & -4.0916 \\
SDAA & -45190.3736 & 7.1574 & -6.6143 & -2.3471 & -4.2672 \\
ODAA & -32312.5246 & 1.0582 & -5.7260 & -2.0682 & -3.6578 \\
\hline 6-311G $(\mathbf{d}, \mathbf{p})$ & & & & & \\
DAA & -30274.5902 & 0.0000 & -5.6522 & -2.2930 & -3.3592 \\
MDAA & -31344.6963 & 2.4538 & -5.9243 & -1.8450 & -4.0793 \\
SDAA & -45203.7810 & 5.9356 & -6.4268 & -2.2685 & -4.1583 \\
ODAA & -32321.4565 & 0.8956 & -5.6265 & -2.0400 & -3.5865 \\
\hline
\end{tabular}

Table 2: Calculated quantum chemical descriptors for non-protonated molecules in gas phase.

\begin{tabular}{lcccccc}
\hline & $\mathbf{I}(\mathbf{e V})$ & $\mathbf{A}(\mathbf{e V})$ & $\chi(\mathbf{e V})$ & $\eta(\mathrm{eV})$ & $\sigma\left(\mathbf{e V}^{-1}\right)$ & $\Delta \mathbf{N}$ \\
\hline 6-31G & & & & & & \\
DAA & 5.4975 & 2.0762 & 3.7868 & 1.7106 & 0.5846 & 0.3020 \\
MDAA & 5.7291 & 1.6443 & 3.6867 & 2.0424 & 0.4896 & 0.2774 \\
SDAA & 6.3688 & 2.1325 & 4.2506 & 2.1182 & 0.4721 & 0.1344 \\
ODAA & 5.4815 & 1.8293 & 3.6554 & 1.8261 & 0.5476 & 0.3189 \\
\hline 6-311G & & & & & & \\
DAA & 5.7336 & 2.3107 & 4.0221 & 1.7114 & 0.5843 & 0.2331 \\
MDAA & 5.9646 & 1.8730 & 3.9188 & 2.0458 & 0.4888 & 0.2202 \\
SDAA & 6.6143 & 2.3471 & 4.4807 & 2.1336 & 0.4687 & 0.0795 \\
ODAA & 5.7260 & 2.0682 & 3.8971 & 1.8289 & 0.5468 & 0.2523 \\
\hline 6-311G $(\mathbf{d}, \mathbf{p})$ & & & & & & \\
DAA & 5.6522 & 2.2930 & 3.9726 & 1.6796 & 0.5954 & 0.2523 \\
MDAA & 5.9243 & 1.8450 & 3.8846 & 2.0396 & 0.4903 & 0.2293 \\
SDAA & 6.4268 & 2.2685 & 4.3476 & 2.0791 & 0.4810 & 0.1136 \\
ODAA & 5.6265 & 2.0400 & 3.8332 & 1.7932 & 0.5577 & 0.2751 \\
\hline
\end{tabular}

interactions. According to Fukui's frontier molecular orbital theory, HOMO and LUMO energies are very useful in understanding the adsorption reactivity of a molecule..$^{29}$ $\mathrm{E}_{\text {номо }}$ describes the electron-donating ability of the inhibitor; higher $\mathrm{E}_{\text {номо }}$ facilitates the electron donation from the inhibitor to the vacant $d$ orbitals of metal atoms. $\mathrm{E}_{\mathrm{Lumo}}$ is related to electron-accepting ability of the inhibitor; lower $\mathrm{E}_{\text {LUMO }}$ indicates high capacity of the inhibitor to receive electrons from metal surface. HOMO and LUMO distribution in the non-protonated dianiline Schiff bases under probe is shown in Figure 4 . The calculated energies corresponding to these frontier orbitals are presented in Table 1. It can be observed that $\mathrm{E}_{\text {номо }}$ values increase in the order: SDAA $<$ MDAA $<$ DAA $<$ ODAA, indicating that the studied inhibitors donate electrons to mild steel surface following the order: ODAA > DAA > MDAA >
SDAA, these results are not in good agreement with the experimental inhibition efficiencies.

The energy gap $(\Delta \mathrm{E})$ : the energy difference between HOMO and LUMO is also an important parameter used to evaluate the inhibitor reactivity towards the metal surface. ${ }^{22}$ As $\Delta \mathrm{E}$ decreases, the chemical reactivity increases leading to an increase in the adsorption of the inhibitor molecules on the metallic surface..$^{30}$ The calculated $\Delta \mathrm{E}$ values for non-protonated molecules under investigation are given in Table 1, it can be seen that the trend of $\triangle \mathrm{E}$ is as follows: DAA > ODAA > MDAA > SDAA, which is not in agreement with the experimental findings.

Electronegativity $(\chi)$ is a chemical property that describes the molecule capability to attract electrons. High inhibition efficiency is expected for the molecules having lower electronegativity because they could easily donate 


\section{6 ?}

DAA HOMO

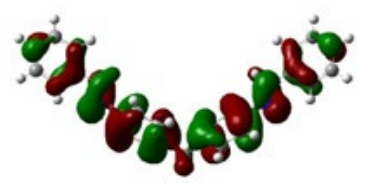

MDAA HOMO

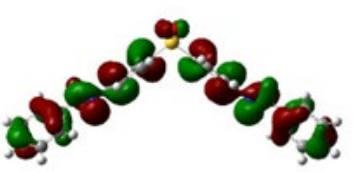

SDAA HOMO

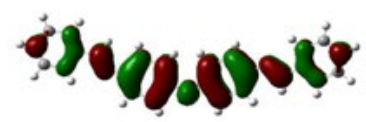

ODAA HOMO

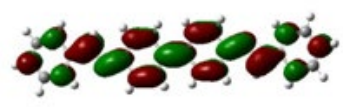

DAA LUMO

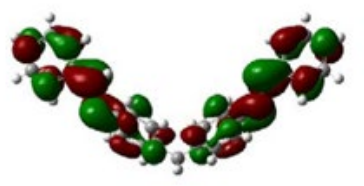

MDAA LUMO

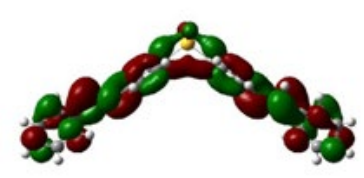

SDAA LUMO

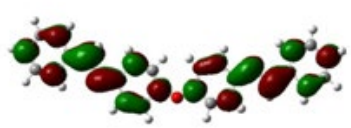

ODAA LUMO
Figure 4: HOMO and LUMO orbitals of non-protonated inhibitor molecules using B3LYP/6-31G calculation level.

their electrons to the metal surface. ${ }^{31}$ Table 2 gives the calculated electronegativity $(\chi)$ data of the studied molecules, it is clear that the calculated electronegativity values exhibit the tendency: SDAA > DAA > MDAA > ODAA, which does not correlate with the experimental inhibition efficiency results.

Global hardness ( $\eta$ ) is a measure of molecule resistance towards electron cloud polarization or deformation of molecules under small perturbations of the chemical reaction. ${ }^{32}$ The inhibitor with the least value of global hardness is expected to have the highest inhibition efficiency. ${ }^{33}$ The calculated global hardness values displayed in Table 2 show that DAA has the lowest global hardness value, which confirms its highest inhibition efficiency.

Global Softness $(\sigma)$ is an important quantum parameter used to explain chemical reactivity of the molecule. The adsorption on metal surface occurs at the part of the molecule where softness has higher value. ${ }^{34}$ It can be seen from Table 2 that the calculated softness values of the studied inhibitors increase as follows: SDAA $<$ MDAA < ODAA $<$ DAA, indicating that DAA has stronger adsorption on metal surface compared to the absorption of MDAA, SDAA, and ODAA, respectively.

The fraction of electrons transferred $(\Delta \mathrm{N})$ from the inhibitor to the metallic surface is calculated using Pearson's formula (Eq. 6). According to Lukovits et al..$^{35}$ the inhibition activity increases with increasing of electron-donating ability of the molecule to the metal surface if $\Delta \mathrm{N}<$ 3.6. It is apparent from Table 2 that $\Delta \mathrm{N}$ values are positive and are below 3.6, indicating the tendency of the tested
Schiff bases to give electrons to mild steel surface. The electron donation of the studied inhibitors increases in the order: SDAA $<$ MDAA $<$ DAA $<$ ODAA, this result is in negative correlation with the experimental results of the inhibition efficiency.

The dipole moment $(\mu)$ results from non-uniform distribution of charges on the various atoms in the molecule. ${ }^{36}$ High dipole moment is required to ensure a better molecule adsorption on metal surfaces. ${ }^{37}$ The dipole moment values presented in Table 1 , show that the trend of the $\mu$ values is: SDAA > MDAA > ODAA > DAA, which does not correlate well with the experimental data. Similar irregularities in the correlation of dipole moment with the experimental inhibition efficiency results have also been reported. ${ }^{38}$

\section{2. Results of the Calculations for Protonated Species}

In acidic solution, corrosion inhibitor compounds can be easily protonated due to the presence of heteroatoms with a number of lone pairs of electrons in their molecular structures. In such cases, it is important to investigate the properties of the corrosion inhibitor in the protonated form and compare it with those of the non-protonated form to find the preferred form of the inhibitor to interact with the metal surface.

In the case of dianiline Schiff bases under investigation, $\mathrm{N}$ atoms in each compound are the possible sites for

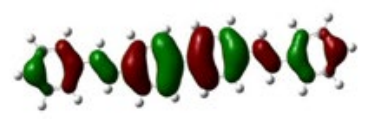

Protonated DAA HOMO

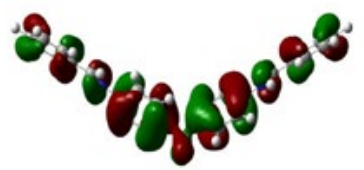

Protonated MDAA HOMO

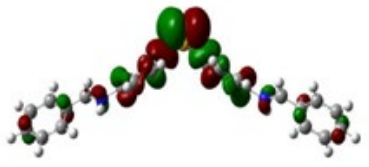

Protonated SDAA HOMO

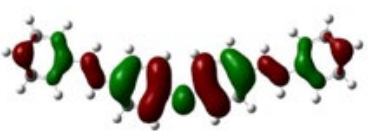

Protonated ODAA HOMO

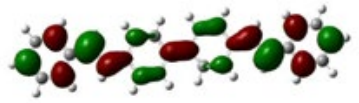

Protonated DAA LUMO

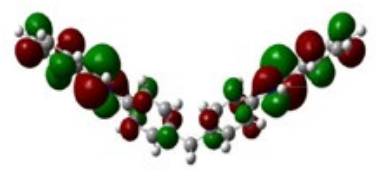

Protonated MDAA LUMO

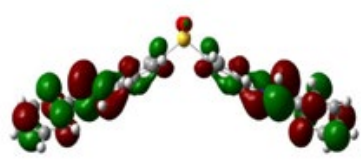

Protonated SDAA LUMO

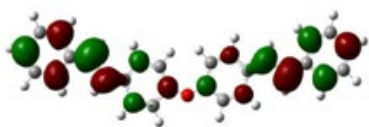

Protonated ODAA LUMO
Figure 5: HOMO and LUMO orbitals of the protonated inhibitor molecules at B3LYP/6-31G level. 
Table 3: Calculated quantum chemical descriptors for protonated molecules in gas phase.

\begin{tabular}{lrrrrr}
\hline & \multicolumn{1}{c}{$\mathrm{TE}(\mathbf{e V})$} & $\boldsymbol{\mu}(\mathbf{D})$ & $\mathrm{E}_{\text {номо }}(\mathrm{eV})$ & $\mathrm{E}_{\text {LUмо }}(\mathrm{eV})$ & $\Delta \mathrm{E}(\mathbf{e V})$ \\
\hline 6-31G & & & & & \\
DAA & -30280.0092 & 0.0005 & -11.3172 & -8.3724 & -2.9448 \\
MDAA & -31349.6019 & 2.9911 & -11.5562 & -8.0977 & -3.4585 \\
SDAA & -45201.3503 & 12.7733 & -11.8510 & -8.3963 & -3.4547 \\
ODAA & -32325.5683 & 2.4108 & -11.0725 & -8.1590 & -2.9135 \\
\hline 6-311G & & & & & \\
DAA & -30285.9332 & 0.0005 & -11.5032 & -8.5425 & -2.9607 \\
MDAA & -31355.7800 & 2.9757 & -11.7743 & -8.2511 & -3.5232 \\
SDAA & -45209.3033 & 12.8562 & -12.0919 & -8.5542 & -3.5377 \\
ODAA & -32332.1408 & 2.4482 & -11.2662 & -8.3324 & -2.9338 \\
\hline 6-311G $(\mathbf{d}, \mathbf{p})$ & & & & & \\
DAA & -30293.9643 & 0.0006 & -11.4840 & -8.5295 & -2.9545 \\
MDAA & -31364.1282 & 3.0031 & -11.7249 & -8.2678 & -3.4571 \\
SDAA & -45222.6089 & 11.8761 & -12.1723 & -8.5209 & -3.6514 \\
ODAA & -32340.9189 & 2.1829 & -11.2466 & -8.2979 & -2.9487 \\
\hline
\end{tabular}

Table 4: Calculated quantum chemical descriptors for protonated molecules in gas phase.

\begin{tabular}{lcrrrrc}
\hline & $\mathbf{I}(\mathbf{e V})$ & $\mathbf{A}(\mathbf{e V})$ & $\chi(\mathbf{e V})$ & $\eta(\mathbf{e V})$ & $\sigma\left(\mathbf{e V}^{-1}\right)$ & \multicolumn{1}{c}{$\Delta \mathbf{N}$} \\
\hline 6-31G & & & & & & \\
DAA & 11.3172 & 8.3724 & 9.8448 & 1.4724 & 0.6792 & -1.7063 \\
MDAA & 11.5562 & 8.0977 & 9.8269 & 1.7292 & 0.5783 & -1.4477 \\
SDAA & 11.8510 & 8.3963 & 10.1236 & 1.7273 & 0.5789 & -1.5352 \\
ODAA & 11.0725 & 8.1590 & 9.6157 & 1.4567 & 0.6865 & -1.6461 \\
\hline 6-311G & & & & & & \\
DAA & 11.5032 & 8.5425 & 10.0228 & 1.4803 & 0.6755 & -1.7573 \\
MDAA & 11.7743 & 8.2511 & 10.0127 & 1.7616 & 0.5677 & -1.4738 \\
SDAA & 12.0919 & 8.5542 & 10.3230 & 1.7688 & 0.5653 & -1.5556 \\
ODAA & 11.2662 & 8.3324 & 9.7993 & 1.4669 & 0.6817 & -1.6972 \\
\hline 6-311G(d,p) & & & & & & \\
DAA & 11.4840 & 8.5295 & 10.0067 & 1.4772 & 0.6769 & -1.7556 \\
MDAA & 11.7249 & 8.2678 & 9.9963 & 1.7285 & 0.5785 & -1.4973 \\
SDAA & 12.1723 & 8.5209 & 10.3466 & 1.8257 & 0.5477 & -1.5136 \\
ODAA & 11.2466 & 8.2979 & 9.7722 & 1.4743 & 0.6783 & -1.6795 \\
\hline
\end{tabular}

protonation. The calculations for the protonated form have been performed using the same basis sets as the case of non-protonated species, the quantum chemical parameters related to the global reactivity of the protonated species are reported in Table 3 and 4.

The electronic distribution of HOMO and LUMO orbitals in the protonated species is presented in Figure 5.

The comparison of $\mathrm{E}_{\text {номо }}, \mathrm{E}_{\mathrm{LUMO}}$, and $\Delta \mathrm{E}$ of the protonated species and those of the non-protonated species revealed that $\mathrm{E}_{\text {номо }}$ for the protonated form is lower than for the non-protonated form, suggesting that the non-protonated form has a greater tendency to donate electrons to the poor metal atoms than the protonated form. $\mathrm{E}_{\mathrm{LUMO}}$ has lower values in the protonated form than in the non-protonated form, which means that the protonated form has a greater tendency to accept elec- trons from the metal than the non-protonated species. The energy gap $(\Delta \mathrm{E})$ values are greater for the protonated form than for the non-protonated form, indicating that the non-protonated species has a greater tendency to adsorb on the metal surface than the protonated species.

The fraction of electrons transferred $(\Delta \mathrm{N})$ values of the protonated species are negative, indicating that the protonated form is more electron deficient than the non-protonated form.

The dipole moment is higher for the protonated species than for the non-protonated species suggesting that dipole-dipole interactions are more predominant in the interaction between the metal surface and the protonated form than in the interaction between the metal surface and the non-protonated form. 


\section{Conclusion}

This study aims to bridge the gap between the corrosion inhibition efficiencies of four dianiline Schiff bases and their electronic and molecular properties. DFT calculations at B3LYP functional with 6-31G, 6-311G, and $6-311 \mathrm{G}(\mathrm{d}, \mathrm{p})$ basis sets were employed at the non-protonated and protonated forms of the studied molecules. It was concluded from this study that:

- DAA has the highest total energy among the studied dianiline Schiff bases, confirming its highest reactivity towards metal surface.

- Quantum parameters such as global hardness $(\eta)$ and global softness $(\sigma)$ support that DAA has the highest inhibition efficiency.

- No direct relationship between the experimental results of the inhibition efficiencies and both gap energy $(\Delta \mathrm{E})$, electronegativity $(\chi)$, the fraction of electrons transferred $(\Delta \mathrm{N})$, and dipole moment $(\mu)$.

- The comparison between the results of the non-protonated species and those of the protonated species showed that the non-protonated form of the dianiline Schiff bases is the preferred form to interact with the metal surface.

Acknowledgment: The authors would like to thank Professor Bachir Abdelmalik from the department of computer science, University of Biskra-Algeria for his English skills.

Funding: This research did not receive any specific grant from funding agencies in the public, commercial, or not-for-profit sectors.

\section{References}

1. Y. Liang, C. Wang, J. S. Li, L. J Wang, J. J. Fu, Int. J. Electrochem. Sci. 2015, 10, 8072-8086.

2. S. A. A. El-Maksoud, A. S. Fouda, Mater. Chem. Phys. 2005, 93, 84-90. DOI:10.1016/j.matchemphys.2005.02.020

3. H. Keles, M. Keles, I. Dehri, O. Serindag, Mater. Chem. Phys. 2008, 12, 173-179. DOI:10.1016/j.matchemphys.2008.05.027

4. L. Guo, X. Ren, Y. Zhou, S. Xu, Y. Gong, S. Zhang, Arab. J. Chem. 2017, 10, 121-130.

DOI:10.1016/j.arabjc.2015.01.005

5. N. O. Eddy, Port. Electrochim. Acta. 2009, 27, 579-589. DOI:10.4152/pea.200905579

6. R. Solmaz, E. A. Sahin, A. Doner, G. Kardas, Corros. Sci. 2011, 53, 3231-3240. DOI:10.1016/j.corsci.2011.05.067

7. O. K. Abiola, N. C. Oforka, Mater. Chem. Phys. 2004, 83, 315322. DOI:10.1016/j.matchemphys.2003.10.001

8. H. D. Lece, K. C. Emregul, O. Atakol, Corros. Sci. 2008, 50, 1460-1468. DOI:10.1016/j.corsci.2008.01.014

9. S. Issaadi, T. Douadi, A. Zouaoui, S. Chafaa, M. A Khan, G. Bouet, Corros. Sci. 2011, 53, 1484-1488.

DOI:10.1016/j.corsci.2011.01.022
10. K. R Ansari, M. A. Quraishi, A. Singh, Corros. Sci. 2014, 79, 5-15. DOI:10.1016/j.corsci.2013.10.009

11. M. Behpour, S. M. Ghoreishi, N. Soltani, M. Salavati-Niasari, Corros. Sci. 2009, 51, 1073-1082.

DOI:10.1016/j.corsci.2009.02.011

12. M. G. V. Satyanarayana, V. Himabindu, Y. Kalpana, M. R Kumar, K. Kumar, J. Mol. Struct.(THEOCHEM). 2009, 912, 113118. DOI:10.1016/j.theochem.2009.01.005

13. T. H. Muster, A. E. Hughes, S. A. Furman, T. Harvey, N. Sherman, S. Hardin, P. Corrigan, D. Lau, F. H. Scholes, P. A. White, M. Glenn, S. J. Garcia, J. M. C. Mol, Electrochim. Acta. 2009, 54, 3402-3411. DOI:10.1016/j.electacta.2008.12.051

14. S. K. Saha, P. Banerjee, RSC Adv. 2015, 5, 71120-71130.

15. S. Erdogan, Z. S. Safi, S. Kaya, D. O. Isin, L. Guo, C. Kaya, J. Mol. Struct. 2017, 1134, 751-761.

DOI:10.1016/j.molstruc.2017.01.037

16. Z. El Adnani, M. Mcharfi, M. Sfaira, M. Benzakour, A. T. Benjelloun, M. Ebn Touhami, Corros. Sci. 2013, 68, 223-230. DOI:10.1016/j.corsci.2012.11.020

17. H. Lgaz, K. Subrahmanya Bhat, R. Salghi, Shubhalaxmi, S. Jodeh, M. Algarra, B. Hammouti, I. H. Ali, A. Essamri, Journal of Molecular Liquids, 2017, 238, 71-83.

DOI:10.1016/j.molliq.2017.04.124

18. S. Chitra, K. S. Parameswari, Int. J. Electrochem. Sci. 2010, 5, 1675-1697.

19. C. O. Gretir, B. Mihci, G. Bereket, J. Mol. Struct. (THEOCHEM). 1999, 488, 223-231.

DOI:10.1016/S0166-1280(99)00033-0

20. S. G. Zhang, W. Lei, M. Z. Xia, F. Y. Wang, J. Mol. Struct. (THEOCHEM). 2005, 732, 173-182.

DOI:10.1016/j.theochem.2005.02.091

21. I. B. Obot, S. Kaya, C. Kaya, B. Tuzun, Res Chem Intermed. 2016, 42, 4963-4983. DOI:10.1007/s11164-015-2339-0

22. A. Zarrouk, I. El Ouali, M. Bouachrine, B. Hammouti, Y. Ramli, E. M. Essassi, I. Warad, A. Aouniti, R .Salghi, Res Chem Intermed. 2013, 39, 1125-1133.

DOI:10.1007/s11164-012-0671-1

23. T. Koopmans, Physica E. 1934, 1, 104-113.

24. R. G. Pearson, Inorg. Chem. 1988, 27, 734-740. DOI:10.1021/ic00277a030

25. S. Martinez, Mater. Chem. Phys., 2003, 77, 97-102. DOI:10.1016/S0254-0584(01)00569-7

26. R. G. Pearson, Coord. Chem. Rev., 1990, 100, 403-425. DOI:10.1016/0010-8545(90)85016-L

27. A. Kokalj, Chem. Phys., 2012, 393, 1-12. DOI:10.1016/j.chemphys.2011.10.021

28. E .E Ebenso, M. M.Kabanda, T. Arslan, M. Saracoglu, F. Kandemirli, L. C. Murulana, K. A. Singh, K. S. Shukla, B. Hammouti, K. F. Khaled, M. A. Quraishi, I. B. Obot, N. O. Eddy, Int. J. Electrochem. Sci. 2012, 7, 5643-5676.

29. K. Ramya, K. K. Anupama, K. M. Shainy, Egypt. J. Petrol. 2017, 26, 421-437. DOI:10.1016/j.ejpe.2016.06.001

30. I. B. Obot, Z. M. Gasem, Corros. Sci. 2014, 83, 359-366. DOI:10.1016/j.corsci.2014.03.008

31. A. Dutta, S. K. Saha, P. Banerjeeb, D. Sukul, Corros. Sci. 2015, 98, 541-550. DOI:10.1016/j.corsci.2015.05.065 
32. N.O. Obi-Egbedi, I. B. Obot, M. I. El-Khaiary, S. A. Umoren, E. E. Ebenso, Int. J. Electrochem. Sci. 2011, 6, 5649-5675.

33. E. E. Ebenso, D. A. Isabirye, N. O. Eddy, Int. J. Mol. Sci. 2010, 11, 2473-2498. DOI:10.3390/ijms11062473

34. R. Hasanov, M. Sadikoglu, S. Bilgic, Appl. Surf. Sci. 2007, 253, 3913-3921. DOI:10.1016/j.apsusc.2006.08.025

35. I. Lukovits, E. Kalman, F. Zucchi, Corrosion. 2001, 57, 3-8. DOI:10.5006/1.3290328
36. O. Kikuchi, Quant. Struct-Act. Relat. 1987, 6, 179-184. DOI:10.1002/qsar.19870060406

37. X. Li, S. Deng, H. Fu, T. Li, Electrochim. Acta. 2009, 54, 40894098. DOI:10.1016/j.electacta.2009.02.084

38. A. El Assyry, B. Benali, B. Lakhrissi, M. El Faydy, M. Ebn Touhami, R. Touir, M. Touil, Res Chem Intermed. 2015, 41, 34193431. DOI:10.1007/s11164-013-1445-0

\section{Povzetek}

S kvantno kemijskimi računi na nivoju DFT/B3LYP teorije s 6-31G, 6-311G in 6-311G $(\mathrm{d}, \mathrm{p})$ smo proučevali inhibicijo korozije jekla v $1 \mathrm{M} \mathrm{H}_{2} \mathrm{SO}_{4}$ s štirimi dianilinskimi Schiffovimi bazami N,N'-Bis (benziliden) -4,4'-dianilin (DAA), N,N'Bis (benziliden) -4,4'-metilendianilin (MDAA), N, N , Bis (benziliden) -4,4'-sulfonildianilin (SDAA) in N,N'-Bis (benziliden) -4,4'-oksidianilin (ODAA). Izračunali smo kvantne kemijske parametre: $\mathrm{E}_{\mathrm{HOMO}}, \mathrm{E}_{\mathrm{LUMO}}$, energijsko vrzel $(\Delta \mathrm{E})$, dipolni moment $(\mu)$, globalno mehkost $(\sigma)$ in globalno trdnost $(\eta)$, s katerimi smo razložili reaktivnost in selektivnost preučevanih inhibitorje. 